\title{
Solar Dryer Application for Olive Oil Mill Wastes
}

\author{
Irene Montero *, María Teresa Miranda, Francisco José Sepúlveda, José Ignacio Arranz, \\ Carmen Victoria Rojas and Sergio Nogales
}

Received: 9 September 2015; Accepted: 7 December 2015; Published: date

Academic Editor: Animesh Dutta

Department of Mechanical Engineering, Energy and Materials, Industrial Engineering School, University of Extremadura, Av. Elvas s/n, 06006 Badajoz, Spain; tmiranda@unex.es (M.T.M.); fsepulveda@unex.es (F.J.S.); jiarranz@unex.es (J.I.A.); cvrojas@unex.es (C.V.R.); senogalesd@unex.es (S.N.)

* Correspondence: imontero@unex.es; Tel.: +34-924-289-300 (ext. 86725)

\begin{abstract}
Global waste production has raised recently due to numerous agricultural and industrial activities. Among other actions devoted to waste reduction, revaluation seems to be the most advantageous one from an environmental and economic point of view. In the olive oil sector, by-product management (namely olive pomace, olive mill wastewater, and sludge residue) poses serious problems for companies, with the energy use of these wastes being a feasible option to solve these problems. Due to their high moisture content, drying constitutes the main stage for a possible bio-fuel conversion. This research work deals with the analysis of drying for the three main wastes from olive oil by using a prototype dryer. This equipment has different working regimes depending on the kind of convection (natural or forced for passive and active mode, respectively), the incidence of solar radiation on the product (indirect or mixed type) and the use of an additional system for energy supply (hybrid type). From the results, it could be said that all the wastes were suitable for solar drying. However, drying conditions were different for each case. Olive pomace and olive mill wastewater showed promising results for solar drying application in mixed active mode. Concerning sludge residue, its special physical structure could employ the use of turners for drying, in order to improve heat transfer to the product. Moreover, hybrid active mode enabled a considerable reduction in drying time, being an aspect to take into account for its use during low solar radiation or at night time.
\end{abstract}

Keywords: drying kinetics; thin layer; olive pomace; olive mill wastewater; sludge residue

\section{Introduction}

In a global context where waste production increases constantly, its revaluation is becoming more and more important, from an environmental and economic point of view, implementing new measures and procedures that ensure the correct use of by-product recycling is necessary. In order to attain this goal, the use of wastes as fuels or other ways for energy generation is an essential part of sustainable strategies.

The olive oil industry is very important in the worldwide economy. Mediterranean countries produce over $98 \%$ of olive oil in the world (around 2.5 million tons per year), increasing $40 \%$ in the last decade [1].

Spain is the largest olive oil producer and exporter in the world (48\%) [2], way ahead of Italy, which ranks second (21\%). Some regions, such as Andalusia, Castilla-La Mancha and Extremadura, located in the south of Spain, represent $93 \%$ of national production, with over 2 million hectares of olive grove.

For olive processing, two techniques are currently used: the traditional system or three-phase extraction system, with which by-products such olive pomace $(\mathrm{OP})$ and olive mill wastewater (OMW) are obtained; and the two-phase extraction system, whose main waste is sludge residue 
(SLG). The difference in material balance for these procedures might be summarized in water addition reduction in two-phase extraction system, with the resulting increase in solid waste generation (SLG) and the considerable reduction in liquid waste (OMW). Material balances of the oil mill by-products resulting are shown in Table 1 [3].

Table 1. The input-output mass balance $(\mathrm{kg})$ of the olive oil process.

\begin{tabular}{|c|c|c|c|c|c|}
\hline \multirow{2}{*}{ Olive processing } & \multirow{2}{*}{\multicolumn{2}{|c|}{ Input products }} & \multicolumn{3}{|c|}{ Output } \\
\hline & & & Pomace & Wastewater & Oil \\
\hline \multirow{3}{*}{ A three-phase process } & Olive paste & 100 & - & - & - \\
\hline & Process water & 90 & - & - & - \\
\hline & Total & 190 & 62 & 115 & 13 \\
\hline \multirow{3}{*}{ A two-phase process } & Olive paste & 100 & - & - & - \\
\hline & Process water & 15 & - & - & - \\
\hline & Total & 115 & 87 & 15 & 13 \\
\hline
\end{tabular}

Olive pomace is a solid waste composed of pulp, stone, waste oil and water in varying proportions depending on the technology. Usually, olive pomace is processed again by extractors in order to obtain waste oil, generating a new waste with less moisture and higher heating value that is suitable for biofuel use [4]. Olive mill wastewater is a liquid waste that comes from water, contained in olives itself and washing process. It is blackish and usually contains small quantities of oil and pulp. It constitutes a very pollutant waste, due to its high BOD (biochemical oxygen demand) and COD (chemical oxygen demand) levels [5]. Sludge residue is a semi-solid compound made of olive mill wastewater and olive pomace, produced in high quantities and causing environmental impact. It has high moisture percentage, which makes suitable transport and storage systems necessary.

Even though two-phase technology aimed to reduce environmental problems concerning traditional systems, its massive implementation has caused a considerable increase in sludge residue production.

In this regard, the management of the above-mentioned wastes implies a serious problem for olive oil industries, because of their high environmental pollution and the expensiveness of their treatment [6]. Waste revaluation, along with its positive effect on the environment, would enable significant operating and economic improvements for olive oil companies.

Among the different treatments and removal techniques of these wastes (anerobic digestion, composting, centrifugation, floculation, etc.), their use as a soil improver, with or without composting, is included among the most used options in practice, because of their beneficial effects, simplicity, and low costs $[7,8]$. Thermal procedures also represent one of the most used options in practice, with drying as the first treatment in order to revaluate wastes as biofuels.

Drying kinetics of wastes in olive oil industry has been studied by several researchers, by using fluidized beds [9], convective dryers [10], microwave-convective dryers [11] and solar dryers of different kinds (passive, active and hybrid) [12-14].

Solar drying is considered a technique with high potential for by-product reuse. Although solar drying has been used for food products drying, its use for wet by-products has several advantages.

Passive mode is the simplest kind of operation, with the lowest initial investment. However, active mode enables more independence from environmental conditions, allowing a more effective drying process. Finally, hybrid mode makes higher variable control possible, as well as it works with low isolation [15].

In the south of Spain, the use of renewable energy sources, such as solar energy, plays an important role in the drying of these kind of wastes, due to the concurrence of two important factors: the abundance of olive oil industries (availability of by-products) in areas with the highest solar radiation in Europe.

Currently, one of the most important options for energy use of biomass wastes consists of pelletizing and its subsequent application in industrial boilers. There are some research works that analyze densification of wastes from the olive oil industry, with satisfactory results, although their 
high moisture could imply high costs and therefore a problem to be solved [16,17]. Drying kinetics studies might contribute to reducing this cost and improving the efficiency of pelletizing.

For all those reasons, the use of solar drying for by-products from the olive oil industry might imply a viable option in order to revaluate wastes for their use as bio-fuels.

In the present research work, different kinds of solar drying are analyzed for the three above-mentioned wastes, with the aim of assessing their possible technical implementation.

\section{Materials and Methods}

The analyzed wastes came from two oil mills located in Extremadura region, in the south-west of Spain. OP and OMW samples were obtained from a three-phase extraction system, whereas SLG samples were obtained from a two-phase extraction system. Table 2 shows the physical-energy characterization for the wastes.

Table 2. Physical-energy characterization. wb, wet basis; db, dry basis.

\begin{tabular}{cccc}
\hline \multirow{2}{*}{ Property } & \multicolumn{3}{c}{ Wastes } \\
\cline { 2 - 4 } & Olive Pomace (OP) & Olive Mill Wastewater (OMW) & Sludge Residue (SLG) \\
\hline$M(\% \mathrm{wb})$ & $50-58$ & $88-92$ & $68-72$ \\
$B D\left(\mathrm{~kg} / \mathrm{m}^{3} \mathrm{wb}\right)$ & 703 & 1022 & 1065 \\
$V M(\% \mathrm{db})$ & 83.50 & 78.27 & 80.18 \\
$F C(\% \mathrm{db})$ & 12.17 & 11.41 & 15.58 \\
$\mathrm{Ash}(\% \mathrm{db})$ & 4.33 & 10.32 & 4.24 \\
$H H V(\mathrm{MJ} / \mathrm{kg} \mathrm{db})$ & 21.18 & 25.14 & 28.14 \\
$L H V(\mathrm{MJ} / \mathrm{kg} \mathrm{db})$ & 17.26 & 7.50 & 22.26 \\
\hline
\end{tabular}

Whereas moisture is the main parameter that was analyzed in this paper, it was interesting to include some of the most significant physical-energy properties of the wastes, especially when one of the objectives is the energy use of by-products.

The dryer, described in full detail by Montero et al. [18] and installed in University of Extremadura (Badajoz, Spain), has a flat-plate solar collector, a drying chamber for two trays with product, an energy supply system and a chimney for exhaust air, as well as different auxiliary elements for operating, control, and measuring. The dryer works as follows: the collector picks up solar radiation, heating the air and reducing its relative humidity. Afterwards, the air enters the drying chamber, where it is put in contact with the products and reduces their moisture. Finally, the air goes out through the chimney with less temperature and higher relative humidity.

Figure 1 shows the equipment: 1 -temperature and relative humidity thermocouple; 2 -speed sensor; 3-product temperature thermocouple; 4-resistors; 5-balance; 6-fan; 7-folding hood; 8-movement wheels; 9-drying tray; 10-lock system; 11-insulation; 12-absorbing surface; 13-polycarbonate; 14-folding glass doors; 15-control panel; 16-chimney; 17-support for radiation simulator; 18-weather station; 19-transmission and control system; 20-personal computer. The equipment has six working regimes (Table 3), depending on the kind of convection (natural or forced for passive or active mode, respectively), the absence or incidence of solar radiation on the product (indirect or mixed types, respectively) and the use of additional systems to supply energy (hybrid type).

In passive mode, the air moves naturally as a consequence of density variation, due, in turn, to temperature changes. However, in active mode, forced convection is provoked by the use of a fan located in the upper part of the drying chamber.

On the other hand, indirect, mixed and hybrid types are based on different combinations of the following options: air heating in the collector, direct solar radiation on the product and the use of resistors in order to improve air heating.

In active mode, the speed of the fan was fixed to generate two different air mass flows, $q 1$ and q2, with 0.22 and $0.24 \mathrm{~kg} / \mathrm{s}$, respectively. In previous studies, devoted to startup dryer 
optimization [12], the first value was considered to be optimum for active mode operation in this equipment, reaching the highest air temperature within the drying chamber.
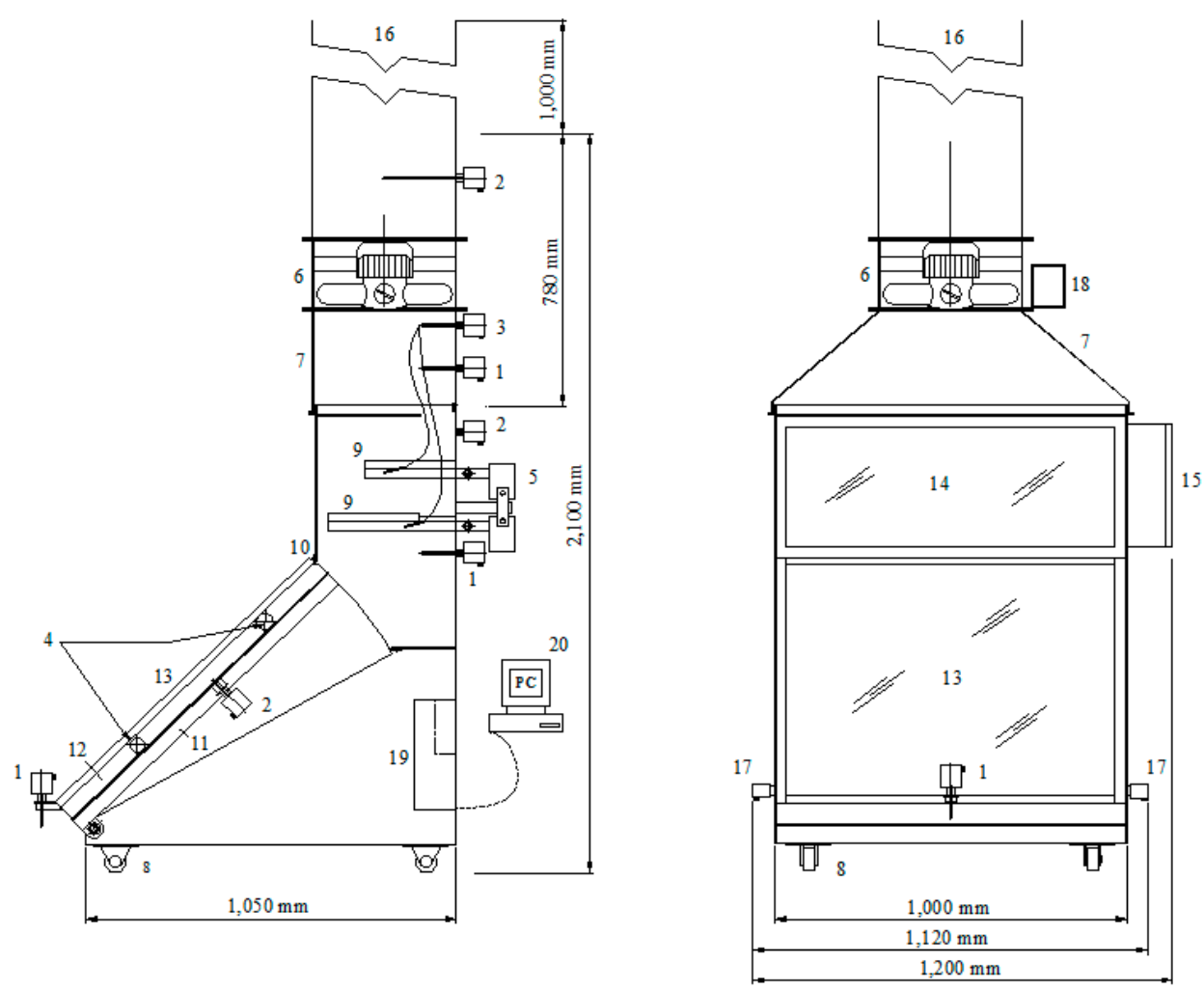

Figure 1. Solar dryer.

Table 3. Operating modes of the solar dryer. $V$, on; -, off.

\begin{tabular}{ccccc}
\hline Mode & Type & Pre-Heating & Solar Radiation & Resistors \\
\hline \multirow{4}{*}{ Passive } & Indirect & $\sqrt{ }$ & - & - \\
& Mixed & $\sqrt{ }$ & $\sqrt{ }$ & - \\
& Hybrid & $\sqrt{ }$ & $\sqrt{ }$ & $\sqrt{ }$ \\
\hline \multirow{4}{*}{ Active } & Indirect & $\sqrt{ }$ & - & - \\
& Mixed & $\sqrt{ }$ & $\sqrt{ }$ & - \\
& Hybrid & $\sqrt{ }$ & $\sqrt{ }$ & $\sqrt{ }$ \\
\hline
\end{tabular}

The assays with hybrid type were carried out with the two 1-kW resistors working continuously.

Different assays were done for each working type of the equipment. In spite of climatological factors, the assays were carried out under similar ambient conditions, as much as possible (from May to September), monitoring the process by using a meteorological station (WatchDog Data Logger 450, Spectrum Technologies, Inc., Aurora, Illinois, USA). The assays were done in triplicate for each waste and operating type.

For all cases, 2 kilograms of each product was uniformly placed (forming 20-40 mm layers) on stainless steel trays (perforated for OP and non-perforated for OMW and SLG), monitoring certain variables such as weight loss, dry air temperature, relative humidity in air, product temperature, global radiation on the horizontal surface of the collector, and wind speed, among others.

The assays lasted until moisture in products was $20 \pm 0.50(\% \mathrm{wb})$, for all cases.

Moisture determination was carried out through the following equations:

$$
M(\mathrm{wb})=\frac{m_{w}}{m_{s}+m_{w}} \cdot 100(\% \mathrm{wb})
$$




$$
M(\mathrm{db})=\frac{m_{w}}{m_{s}} \cdot 100(\% \mathrm{db})
$$

Given the different moisture levels in the three wastes, and with the aim of comparing drying kinetics regardless of initial moisture, in the present work moisture ratio $(M R)$, defined as the quotient between moisture content at any time $\left(M_{t}\right)$ and initial moisture $\left(M_{0}\right)$, was used, according to Equation (3).

$$
M R=\frac{M_{t}}{M_{0}}
$$

Finally, efficiency levels depending on the operating mode (passive, mixed active, and hybrid active) of the dryer, were measured by Equations (4)-(6), respectively $[19,20]$.

$$
\begin{gathered}
\eta=\frac{\left(W_{0}-W_{t}\right) \cdot L}{I_{t} \cdot A_{c}} \\
\eta=\frac{\left(W_{0}-W_{t}\right) \cdot L}{I_{t} \cdot A_{c}+E_{f}} \\
\eta=\frac{\left(W_{0}-W_{t}\right) \cdot L}{\left(I_{t} \cdot A_{c}+E_{f}\right)+E_{a}}
\end{gathered}
$$

Data corresponding to drying kinetics of OP were analyzed by Montero et al. [18], being the basis for the present research work.

\section{Results and Discussion}

\subsection{Initial Tests}

Drying is a fundamental stage for waste revaluation as a biofuel. High moisture content implies that some heat from combustion is used to evaporate water in biofuels, reducing the useful energy. Lower moisture allows a higher flame temperature (with better temperature gradients and heat transfer), as well as shorter residence time in the combustion chamber [21].

Therefore, combustion yield in biomass boilers increases when moisture decreases. The drying process contributes to reducing transport costs [22].

Energy requirements for waste and by-product drying depends on their nature, and it can be assessed by measuring initial and final moisture. In addition, each product has a certain drying rate and maximum temperature ranges (if it is used in food) [15].

Drying kinetics of by-products is dependent on several parameters, both external (ambient temperature and humidity, solar radiation, etc.) and internal (temperature and humidity inside the drying chamber, flow mass, and speed of air, among others).

An increase in dry air temperature, with the subsequent decrease in relative humidity, causes a considerable reduction in drying time [23]. In turn, concerning solar dryers, an increase in solar radiation causes higher temperatures in drying chambers and, therefore, shorter operating times. Finally, the increase in air speed through the product reduces drying ratio, with a limit value for this speed from which drying times do not decrease significantly [24].

The first assays were carried out in active mode (forced convection, q1), with the aim of comparing the suitability of hybrid and indirect types. The obtained results are shown in Figures 2 and 3.

In this way, a significant improvement in drying times can be observed when mixed type was used for the three by-products ( $43 \%, 64 \%$ and $25 \%$ for OP, OMW and SLG, respectively). Therefore, this option is preferable for those wastes set aside for energy use, whose quality parameters are not important (for instance, products for food) [25-27]. 


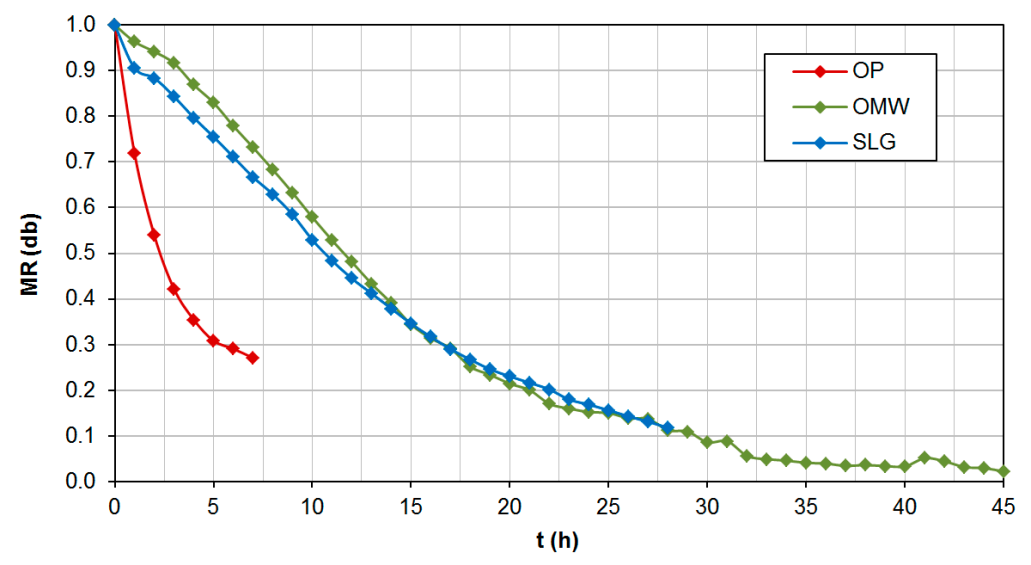

Figure 2. Moisture ratio $(M R)(\mathrm{db})$ indirect active mode.

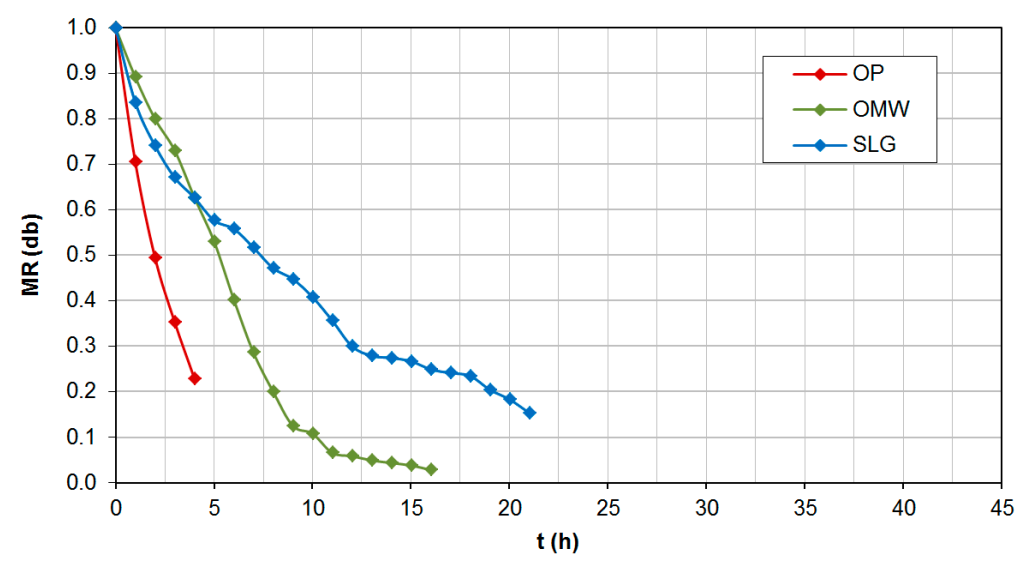

Figure 3. $M R(\mathrm{db})$ mixed active mode.

Even though OMW and SLG wastes showed similar results for indirect active mode, there were some differences for mixed type. After $5 \mathrm{~h}$ of the assay and a moisture ratio value of $0.6(\mathrm{db})$, a reduction in drying time for OMW waste can be observed, despite its initial high moisture. This circumstance could be due to heterogeneity and the particular physical structure of SLG (that is a mixture of several products) that promotes sugar caramelization and the subsequent ball formation that occludes water, avoiding total water evaporation [28].

Once the advantages of mixed type versus indirect types were observed, a comparison between passive and active operating modes was carried out. Thus, Figure 4 shows moisture ratio evolution over time for mixed passive mode.

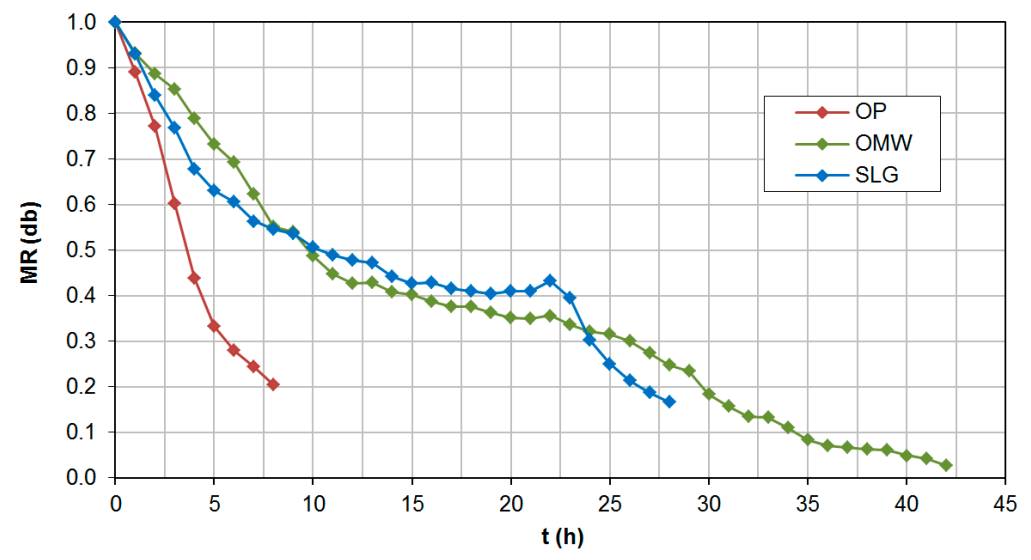

Figure 4. $M R(\mathrm{db})$ mixed passive mode. 
Shorter drying times were obtained for OP, although these values were higher than the obtained ones for mixed active mode (Figure 3). SLG showed shorter drying times than OMW (even though it experienced reabsorption at the 22nd hour of the assay), being the opposite for mixed active mode. This could be due to the lack of control over operating conditions in the chamber for natural convection, which made the drying process worse for OMW (on account of its particular physical structure) and better for SLG.

In this way, through active mode, a considerable reduction in drying time (compared to passive mode) was obtained, improving values for OMW wastes as this situation increased moisture removal.

In all cases, drying time was shortened, in mixed active mode, between $25 \%$ and $62 \%$.

\subsection{Influence of Air Mass Flow}

Figures 5-7 show the influence of air mass flow on drying, comparing moisture ratio for the different operating modes of the dryer: mixed passive, mixed active ( $q 1$ and $q 2)$, and hybrid active ( $q 1$ and $q 2$ ).

In all cases, longer drying times were obtained in passive mode. Depending on the operating mode, the drying times were around $2-8 \mathrm{~h}$ for OP, $11-42 \mathrm{~h}$ for OMW, and $10-28 \mathrm{~h}$ for SLG.

In mixed and hybrid active modes, air mass flow was above the optimum value $(q 1)$, not implying a substantial improvement of drying times, because of air temperature reduction in the chamber, decreasing its drying effectiveness [24,29]. In fact, drying times for OP and OMW with higher air mass flow were longer than the initially obtained ones. On the contrary, an increase in mass air flow contributed to faster drying in the case of SLG.

This circumstance was also observed in hybrid active mode, although air temperature in the collector rose due to the use of resistors. SLG drying was, again, shorter as air flow increased.

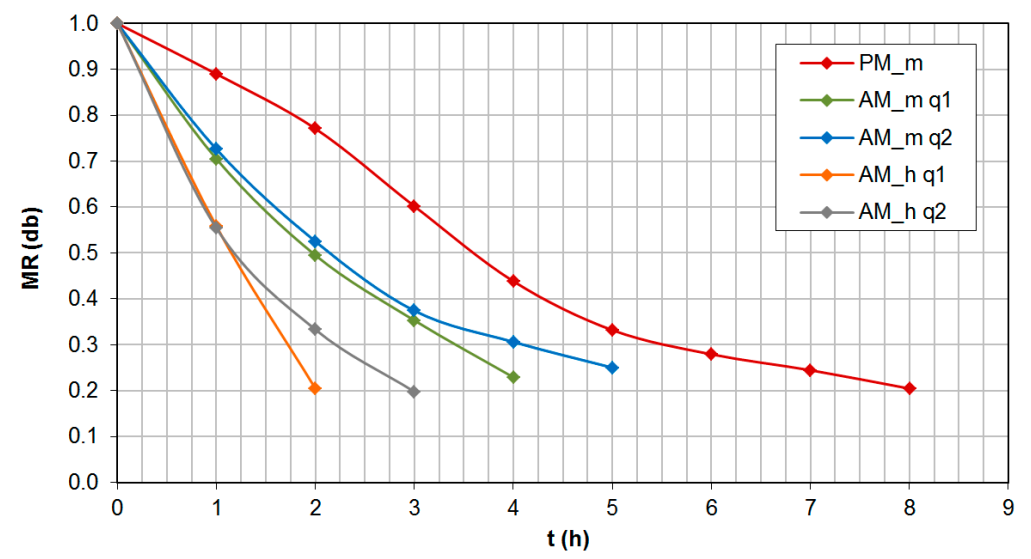

Figure 5. Influence of air mass flow on olive pomace (OP) drying.

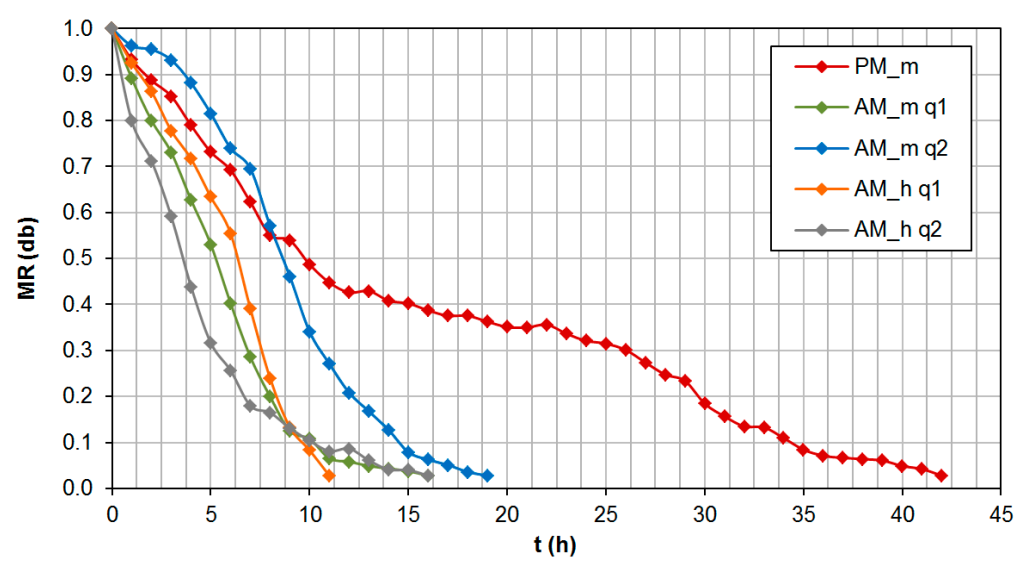

Figure 6. Influence of air mass flow on olive mill wastewater (OMW) drying. 


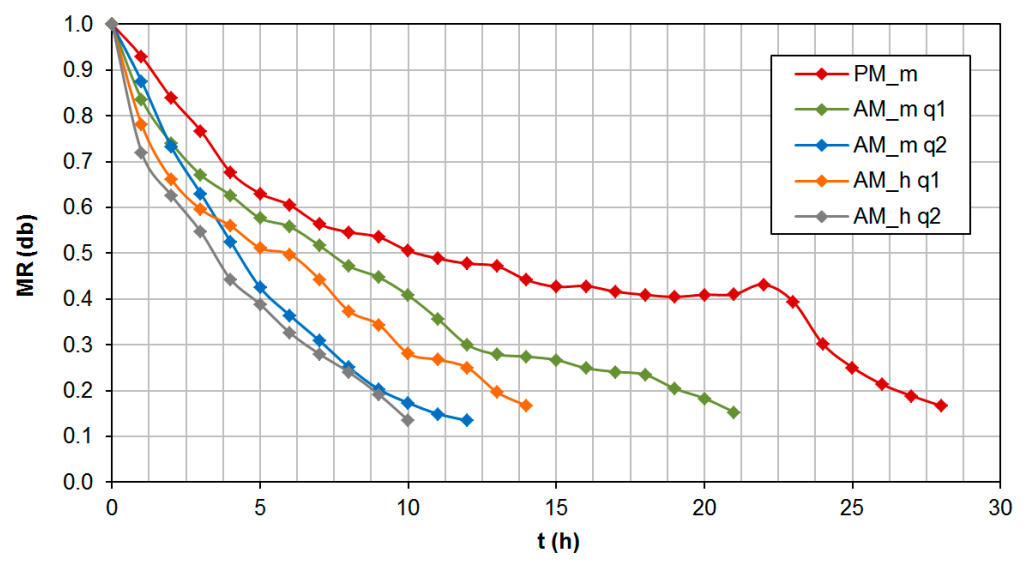

Figure 7. Influence of air mass flow on sludge residue (SLG) drying.

Therefore, and with the different drying behavior that was observed, a suitable and accurate adjustment of air mass flow for each waste is vital in order to select the optimum solar drying system [26]. This fact pointed out the importance of temperature and air mass flow control in solar drying systems, depending on the waste to be dried [18].

Another important parameter for drying kinetics is product temperature. If the moisture ratio is known for several temperature values, simulation models can estimate product temperature from drying kinetics or vice versa. Moreover, through this temperature value it is possible to obtain basic parameters in drying evolution of materials, such as convective rates.

Figures 8-10 show product temperature changes, measured during the assays of the different drying modes: mixed passive, mixed active, and hybrid active modes, the two latter with $q 1$ mass flow. For all the by-products and modes, average air temperature values at the entrance to the chamber were 46,37 and $57^{\circ} \mathrm{C}$, respectively.

For OP waste, product temperature was similar to those found in mixed passive and mixed active modes, at around $35{ }^{\circ} \mathrm{C}$ for natural and forced convection, respectively (due to the use of holed trays in this case). However, in OMW and SLG's case, the temperature found for passive mode was higher than for active mode, being about 35 and $30{ }^{\circ} \mathrm{C}$ for OMW and 43 and $35{ }^{\circ} \mathrm{C}$ for SLG, respectively. As expected, the highest product temperature values were obtained for hybrid active mode, with approximately $65{ }^{\circ} \mathrm{C}$ for OP, $50{ }^{\circ} \mathrm{C}$ for SLG, and $45^{\circ} \mathrm{C}$ for OMW. In this way, in this kind of dryers, the use of an auxiliary energy source is important, in order to reduce the disadvantages related to direct solar drying (such as climatological changes, difficulty at controlling the process, long drying times, etc.) [30], obtaining, in many cases, over 50\% reduction in drying times.

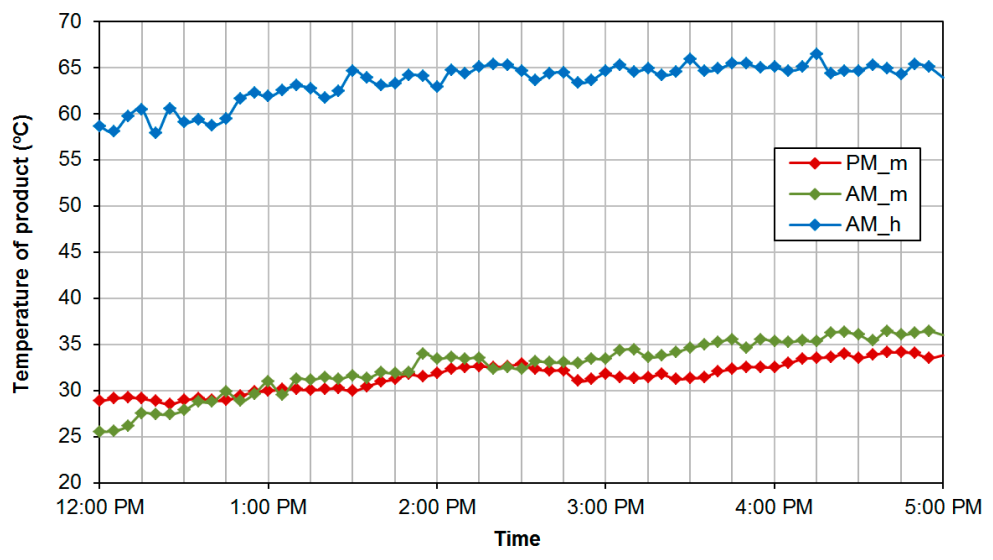

Figure 8. Temperature variation for OP. 


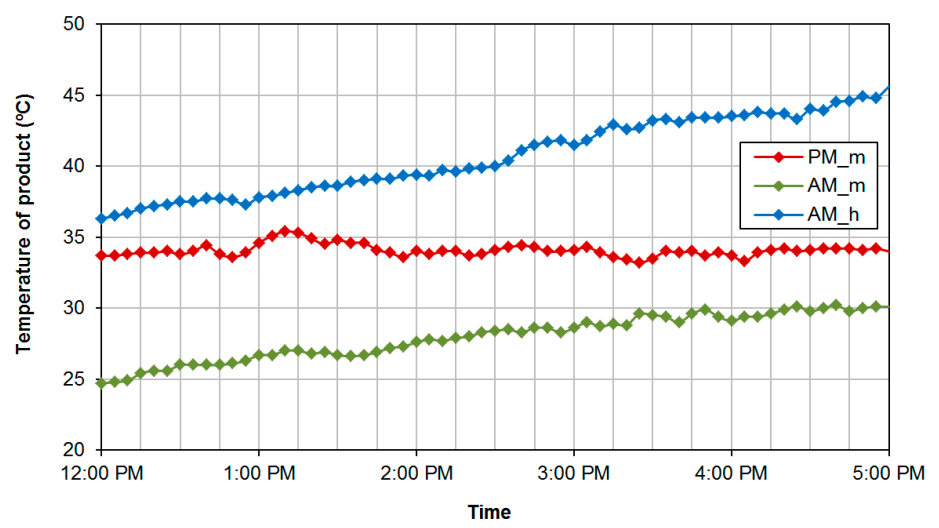

Figure 9. Temperature variation for OMW.

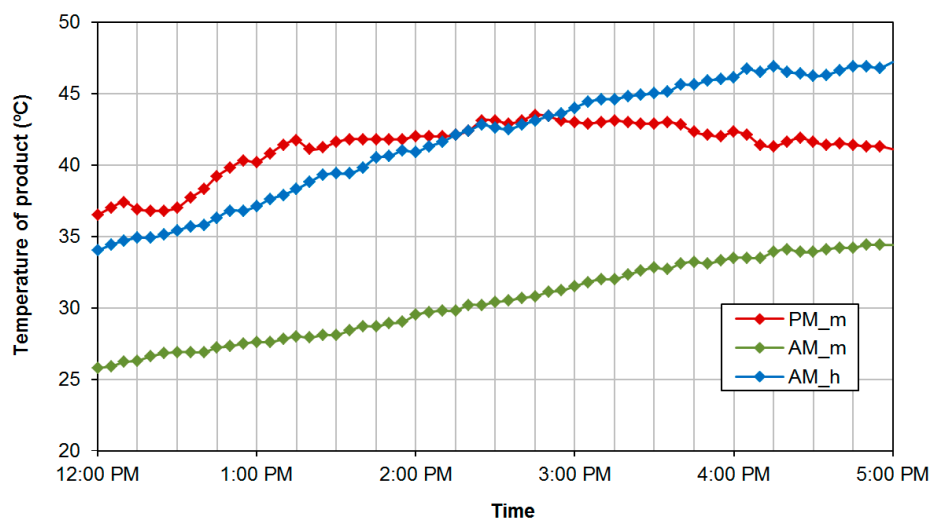

Figure 10. Temperature variation for SLG.

On the other hand, although the former figures have shown moisture ratio and temperature evolution for the products in the lower tray of the dryer, the results obtained for the assays with two trays are also shown, with the aim of observing how the increase in relative humidity in the air (after going through the first tray) reduced its drying capacity when going through the second one.

Figures 11-13 show moisture ratio for the wastes depending on their location in the dryer (lower tray, $l t$, and top tray, $t t)$. For $20 \%$ final moisture $(\mathrm{wb}$ ), fixed as the limit for a product on the lower tray, the corresponding final moisture for the same waste on the top tray was considerably higher, for all the wastes and operating modes, in a range between $15 \%-50 \%$. In turn, drying times increased (two to three times longer) on the top tray. Similar results were obtained by several authors for grape, fig, pea, tomato and onion drying [31] or rice [32].

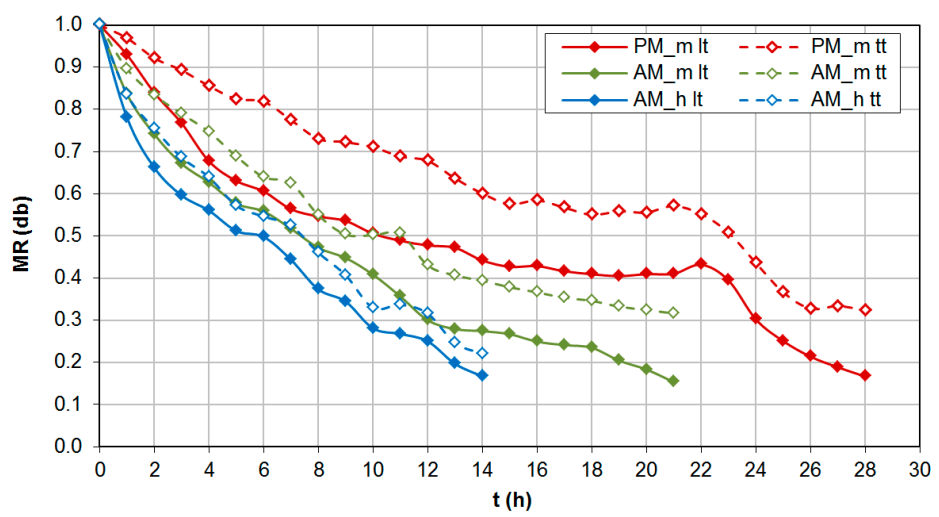

Figure 11. $M R(\mathrm{db})$ for different OP trays. 


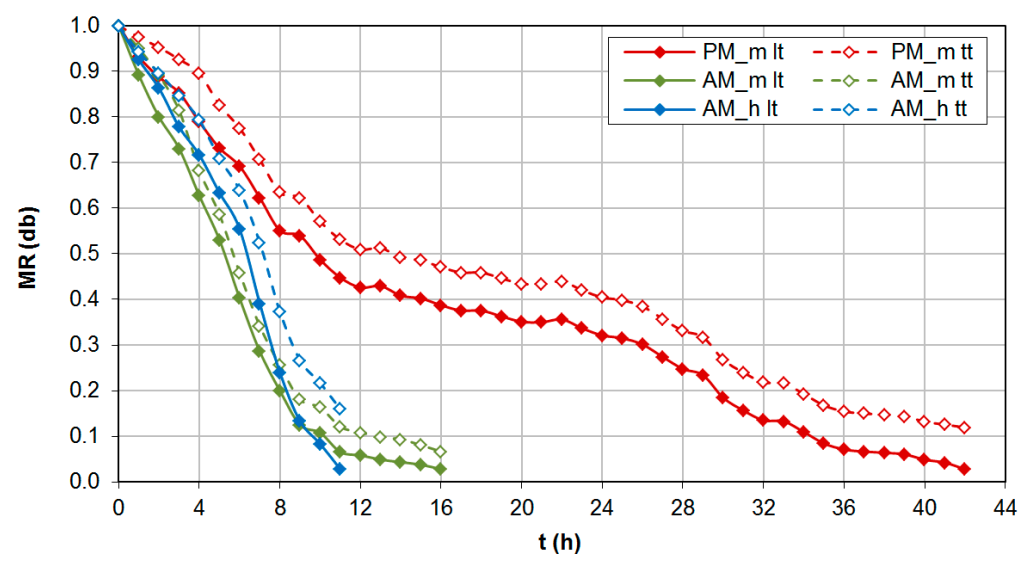

Figure 12. $M R(\mathrm{db})$ for different OMW trays.

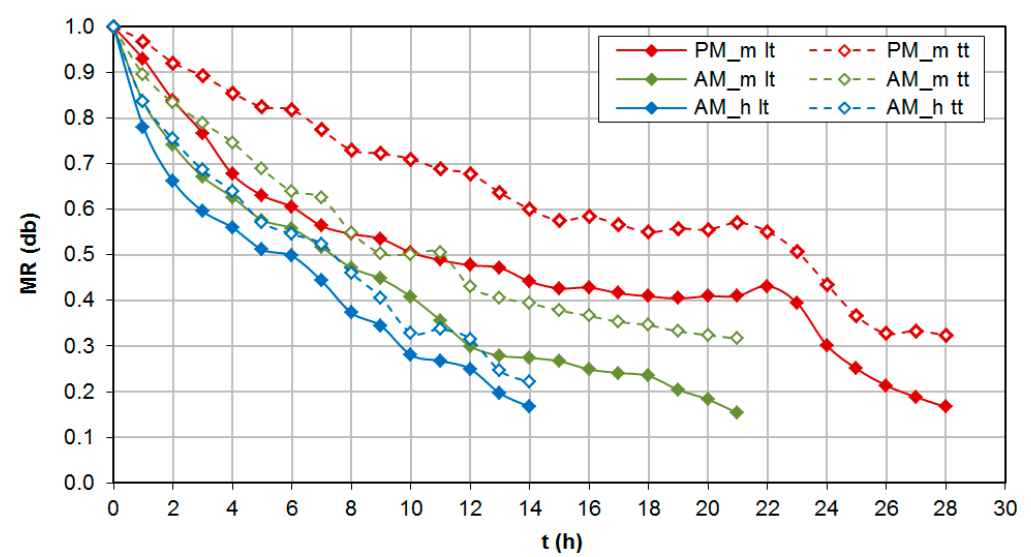

Figure 13. $M R(\mathrm{db})$ for different SLG trays.

Concerning product temperature, the recorded values on the lower tray were higher than the ones obtained on the top tray in all cases, within a range of $2 \%-10 \%$.

\subsection{Influence of External Parameters}

The increase in drying air temperature and its relative humidity decrease cause considerable reductions in drying times [23]. Moreover, temperature and humidity depend on environment variables. In order to analyze moisture ratio reduction concerning temperature and relative humidity variations in drying air, two scenarios ( $a$ and $b$, with $a$ being the most favorable one for drying) were studied within the drying chamber, using the average values for these variables that were shown in Table 4. Defining Sections 1 and 2 as the outside and inside of the drying chamber, respectively, Figures $14-16$ show the MR evolution.

Thus, for the above-mentioned temperature increase and relative humidity decrease (comparing situation $a$ and $b$ ), and 0.3 as $M R(\mathrm{db})$ value, $20 \%, 40 \%$ and $35 \%$ drying time reductions were obtained for OP, OMW and SLG, respectively.

Table 4. Average values.

\begin{tabular}{ccccc}
\hline \multirow{2}{*}{ Situation } & \multirow{2}{*}{ Variables } & \multicolumn{3}{c}{ Wastes } \\
\cline { 3 - 5 } & & OP & OMW & SLG \\
\hline \multirow{2}{*}{$a$} & $M 2 a(\% \mathrm{wb})$ & 10 & 15 & 15 \\
& $T 2 a\left({ }^{\circ} \mathrm{C}\right)$ & 45 & 40 & 40 \\
\hline \multirow{2}{*}{$b$} & $M 2 b(\% \mathrm{wb})$ & 15 & 25 & 20 \\
& $T 2 b\left({ }^{\circ} \mathrm{C}\right)$ & 40 & 30 & 35 \\
\hline
\end{tabular}




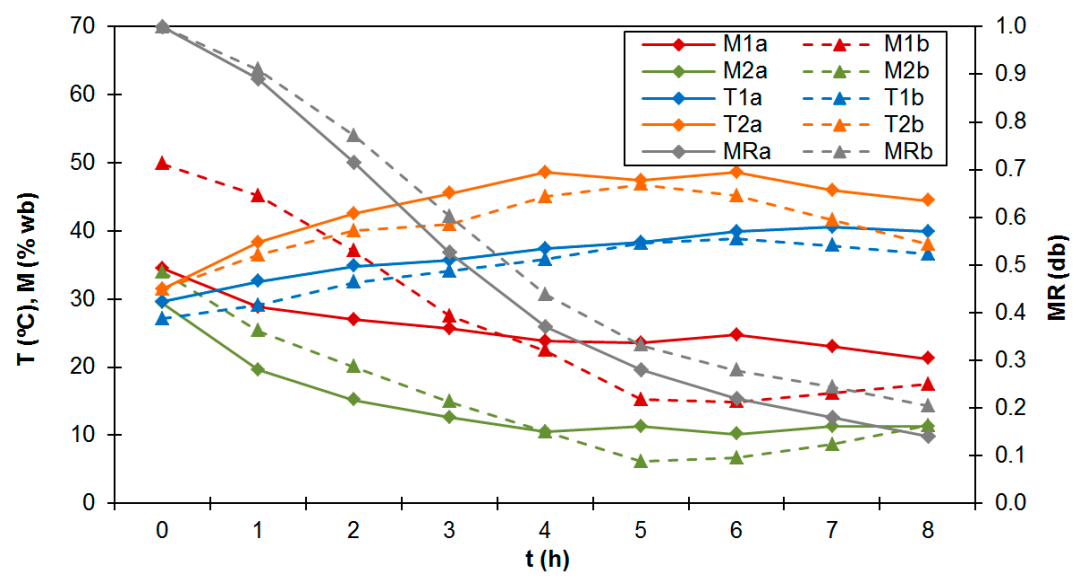

Figure 14. $T, M$ and $M R$ variation of $\mathrm{OP}$ for two situations.

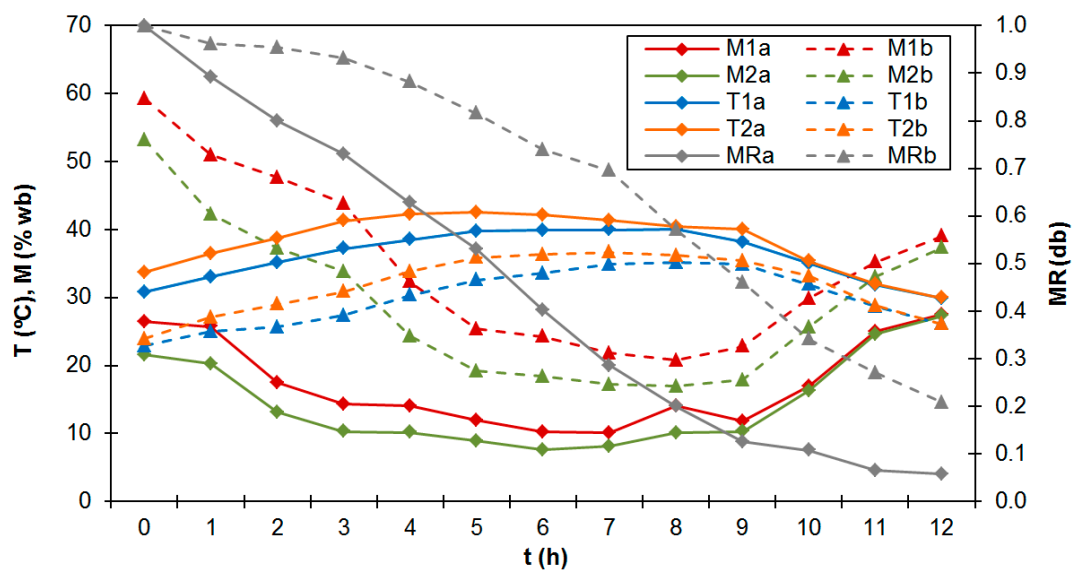

Figure 15. $T, M$ and $M R$ variation of OMW for two situations.

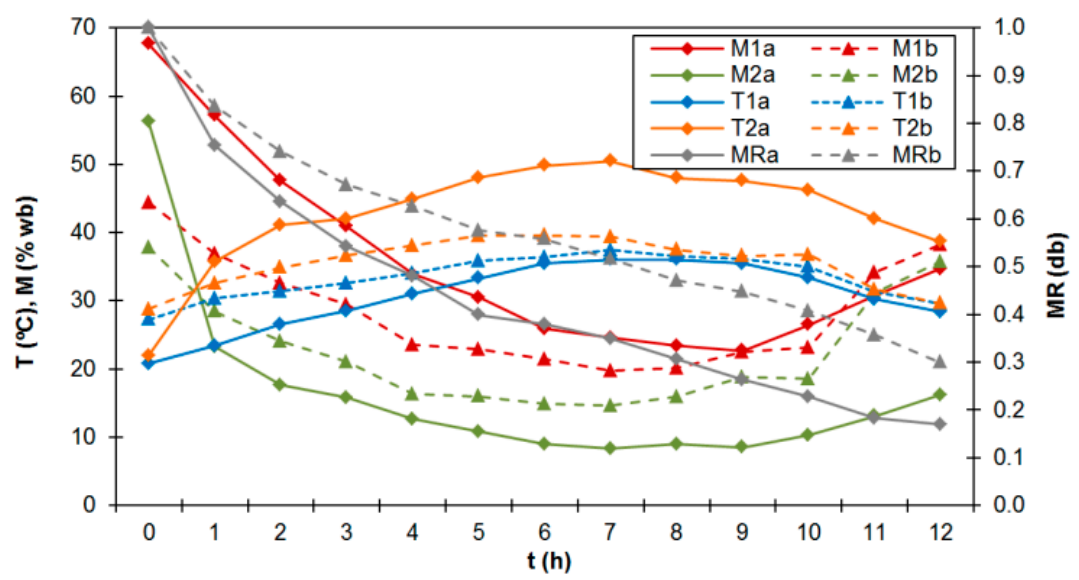

Figure 16. T, $M$ and $M R$ variation of SLG for two situations.

Figure 17 compares product temperature for indirect and mixed active modes, with $q 1$ air mass flow $(0.22 \mathrm{~kg} / \mathrm{s})$. In general, product temperatures were higher in mixed active mode for average radiation between 600 and $900 \mathrm{~W} / \mathrm{m}^{2}$, recording the highest values for OP $\left(35-40{ }^{\circ} \mathrm{C}\right)$, followed by SLG $\left(30-35^{\circ} \mathrm{C}\right)$, and OMW $\left(25-30^{\circ} \mathrm{C}\right)$. 


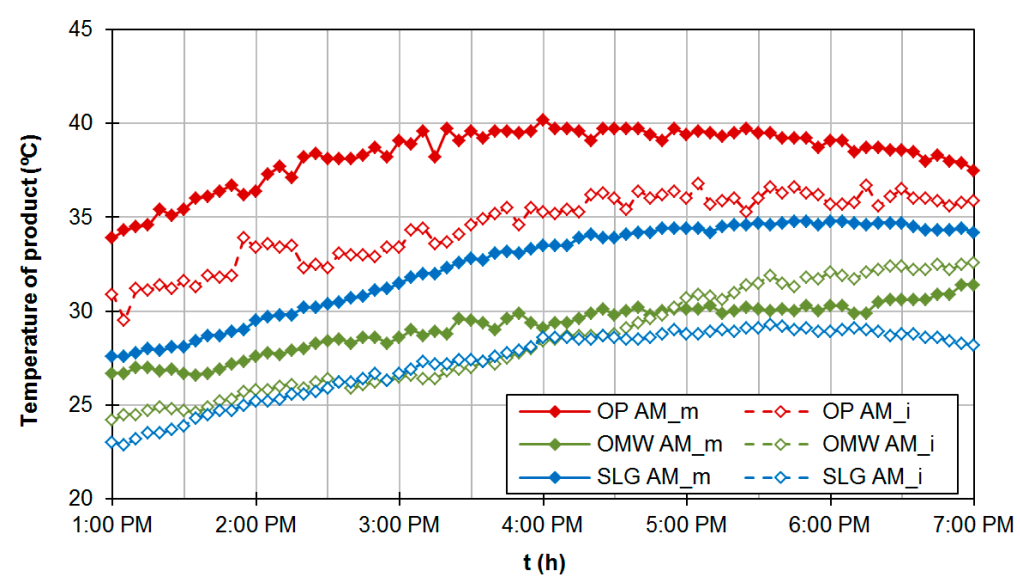

Figure 17. Product temperatures in AM (indirect and mixed types).

\subsection{Drying Time and Efficiency of the Drying Chamber}

Dryer efficiency assesses the overall thermal performance of the system, being a measurement for the ratio of used energy for drying.

Table 5 shows the values for mixed passive, mixed active, and hybrid active, considering solar radiation contribution, energy consumption for the fan at $q 1$ regime and resistors during the drying process.

Table 5. Drying efficiency (\%).

\begin{tabular}{cccc}
\hline Mode & OP & OMW & SLG \\
\hline Mixed passive & 15.3 & 14.1 & 13.2 \\
Mixed active & 23.2 & 23.1 & 15.9 \\
Hybrid active & 44.0 & 26.5 & 17.3 \\
\hline
\end{tabular}

Drying efficiency was between $13 \%-44 \%$, analogous to those values obtained in similar dryers $[30,33]$. The highest values for this parameter were obtained for hybrid active mode, followed by mixed active and passive modes. In this way, a qualitative improvement in efficiency for active mode compared to passive mode was observed, higher in OP and OMW $(>50 \%$ and $>60 \%$, respectively) than in SLG (20\%). In turn, it can be observed that drying efficiency for OP, for each operating mode, was higher than the levels for OMW and SLG.

Lower efficiency values were measured for SLG, not observing significant changes in drying efficiency for the different operating modes.

Finally, Table 6 sums up drying time to get $20 \%$ moisture levels $(\mathrm{wb})$, for the most relevant modes and types used in this research work.

Table 6. Drying time (h).

\begin{tabular}{ccccc}
\hline \multirow{2}{*}{ Mode } & \multirow{2}{*}{ Type } & \multicolumn{3}{c}{ Wastes } \\
\cline { 3 - 5 } & & OP & OMW & SLG \\
\hline Passive & Mixed & 8 & 42 & 28 \\
\hline \multirow{3}{*}{ Active $(q 1)$} & Indirect & 7 & 45 & 28 \\
& Mixed & 4 & 16 & 21 \\
& Hybrid & 2 & 11 & 14 \\
\hline
\end{tabular}

In all cases, the use of a mechanical element to contribute to forced convection (for optimum flow), along with the use of an auxiliary energy system, implied the consecution of shorter drying times. The shorter drying times were obtained for OP waste. Drying times for SLG were acceptable and similar to those obtained with other materials in solar dryers. The highest reduction in drying time (from passive mode to active mode) was observed in OMW samples, being a relevant aspect 
due to the fact that this is considered the most problematic waste in olive oil industry from an environmental point of view.

\section{Conclusions}

The most relevant findings in the present work were the following:

There was a great influence of solar radiation and air mass flow on exhaust air temperature and collector efficiency. Moreover, there was a limit flow value from which dryer efficiency was not improved.

The longest drying times were obtained in passive mode, being reduced from active mode between $30 \%$ and $80 \%$.

Concerning product temperature, the highest values were obtained in hybrid mode, pointing out the importance of using an auxiliary energy source during low solar radiation periods or nighttime.

The increase in air temperature, as well as its relative humidity reduction, caused considerable reductions in drying times, between $20 \%$ and $40 \%$, providing suitable values for solar drying use.

The results obtained for OP and OMW wastes, in mixed type, were promising for their solar drying use.

In the case of SLG waste, good drying times were obtained. However, its lower efficiency levels recommend, due to its physical characteristics, the use of turners in order to improve the process and heat transfer and, subsequently, increase solar drying efficiency.

Therefore, this research work shows an alternative to OMW removal-use (a highly pollutant waste). The study that has been carried out enables further knowledge about drying kinetics of olive oil wastes and the results could be extrapolated to a bigger plant, even for other wastes with similar characteristics. For future studies, environmental and economic aspects related to solar drying will be pointed out, as well as some details concerning its implementation on a large scale.

Acknowledgments: We would like to appreciate the "Gobierno de Extremadura" for the support to research groups (GR10151).

Author Contributions: Regarding the contribution of each author to the article, the original idea and work coordination were done by Irene Montero and María Teresa Miranda. The analysis of data was carried out by Francisco José Sepúlveda, José Ignacio Arranz, Carmen Victoria Rojas and Sergio Nogales. Finally, the wording of the conclusions was made by Francisco José Sepúlveda.

Conflicts of Interest: The authors declare no conflict of interest.

\section{Glossary}

$\begin{array}{llll}A c & \text { Area of the collector }\left(\mathrm{m}^{2}\right) & q 1, q 2 & \text { Air mass flow }(\mathrm{kg} / \mathrm{s}) \\ B D & \text { Bulk density }\left(\mathrm{kg} / \mathrm{m}^{3} \mathrm{wb}\right) & T & \text { Temperature }\left({ }^{\circ} \mathrm{C}\right) \\ \mathrm{db} & \text { Dry basis } & t t & \text { Top tray } \\ F C & \text { Fixed carbon }(\% \mathrm{db}) & T & \text { Time }(\mathrm{h}) \\ I_{t} & \text { Solar radiation at time } t\left(\mathrm{~kJ} / \mathrm{m}^{2}\right) & V M & \text { Volatile matter }(\% \mathrm{db}) \\ H H V & \text { High heating value }(\mathrm{MJ} / \mathrm{kg} \mathrm{db}) & W_{0} & \text { Mass of the product at initial time }(\mathrm{kg}) \\ L & \text { Latent heat of vaporization }(\mathrm{kJ} / \mathrm{kg}) & W_{t} & \text { Mass of the product at time } \mathrm{t}(\mathrm{kg}) \\ L H V & \text { Low heating value }(\mathrm{MJ} / \mathrm{kg} \mathrm{db}) & \text { wb } & \text { Wet basis } \\ l t & \text { Lower tray } & A M_{-} h & \text { Hybrid active mode } \\ M & \text { Moisture }(\%) & A M_{-} i & \text { Indirect active mode } \\ M 0 & \text { Initial moisture }(\%) & A M \_m & \text { Mixed active mode } \\ M_{t} & \text { Moisture at time } t(\%) & P M_{-} h & \text { Hybrid passive mode } \\ m_{c} & \text { Mass of the fuel }(\mathrm{kg}) & P{ }_{-} i & \text { Indirect passive mode } \\ m_{s} & \text { Dry mass }(\mathrm{kg}) & P{ }_{-} m & \text { Mixed passive mode } \\ m_{w} & \text { Wet mass }(\mathrm{kg}) & \text { OMW } & \text { Olive mill wastewater } \\ M R & \text { Moisture ratio } & \text { OP } & \text { Olive pomace } \\ E_{a} & \text { Energy from auxiliary power system }(\mathrm{kJ}) & \mathrm{SLG} & \text { Sludge residue } \\ E_{f} & \text { Energy from fan }(\mathrm{kJ}) & & \end{array}$




\section{References}

1. Dermeche, S.; Nadour, M.; Larroche, C.; Moulti-Mati, F.; Michaud, P. Olive mill wastes: Biochemical characterizations and valorization strategies. Process Biochem. 2013, 48, 1532-1552.

2. Parejo, J.M.; Rubio, J.C.; Pérez, S.; Soriano, M. Health and safety management in olive oil mills in Spain. Saf. Sci. 2013, 51, 101-108.

3. Peri, C.; Proietti, P. Olive mill waste and by-products. In The Extra-Virgin Olive Oil Handbook; John Wiley \& Sons, Ltd.: Chichester, UK, 2014; pp. 283-302.

4. García-Maraver, A.; Zamorano, M.; Ramos, A.; Díaz, L.F. Analysis of olive grove residual biomass potential for electric and thermal energy generation in Andalusia (Spain). Renew. Sustain. Energy Rev. 2012, 16, 745-751.

5. Gómez, F.J.; Casanova, P.J.; Palomar, J.M.; Cruz, F. Modeling of olive-oil mill waste rotary dryers: Green energy recovery systems. Appl. Therm. Eng. 2015, 80, 362-373.

6. Miranda, M.T. Thermal Utilization of Biomass. Application to SLG. Ph.D. Thesis, University of Extremadura, Badajoz, Spain, June 10, 2005. (in Spanish)

7. Gigliotti, G.; Proietti, P.; Said-Pullicino, D.; Nasini, L.; Pezzolla, D.; Rosati, L.; Porceddu, P.R. Co-composting of olive husks with high moisture contents: Organic matter dynamics and compost quality. Int. Biodeterior. Biodegrad. 2012, 67, 8-14.

8. Nasini, L.; Gigliotti, G.; Balduccini, M.A.; Federici, E.; Cenci, G.; Proietti, P. Effect of solid olive-mill waste amendment on soil fertility and olive (Olea europaea L.) tree activity. Agric. Ecosyst. Environ. 2013, 164, 292-297.

9. Meziane, S. Drying kinetics of olive pomace in a fluidized bed dryer. Energy Convers. Manag. 2011, 52, 1644-1649.

10. Vega-Gálvez, A.; Miranda, M.; Díaz, L.P.; López, L.; Rodríguez, K., Scala, K.D. Effective moisture diffusivity determination and mathematical modelling of the drying curves of the olive-waste cake. Bioresour. Technol. 2010, 101, 7265-7270.

11. Milczarek, R.R.; Dai, A.A.; Otoni, C.G., McHugh, T.H. Effect of shrinkage on isothermal drying behavior of 2-phase olive mill waste. J. Food Eng. 2011, 103, 434-441.

12. Montero, I. Modeling and Construction of Hybrid Solar Dryer for Biomass by Products. Ph.D. Thesis, University of Extremadura, Badajoz, Spain, November 30, 2005. (in Spanish)

13. VijayaVenkataRaman, S.; Iniyan, S.; Goic, R. A review of solar drying technologies. Renew. Sustain. Energy Rev. 2012, 16, 2652-2670.

14. Sharma, A.; Chen, C.R.; Vu Lan, N. Solar-energy drying systems: A review. Renew. Sustain. Energy Rev. 2009, 13, 1185-1210.

15. Fudholi, A.; Sopian, K.; Ruslan, M.H.; Alghoul, M.A.; Sulaiman, M.Y. Review of solar dryers for agricultural and marine products. Renew. Sustain. Energy Rev. 2010, 14, 1-30.

16. Miranda, T.; Arranz, J.I.; Montero, I.; Román, S.; Rojas, C.V.; Nogales, S. Characterization and combustion of olive pomace and forest residue pellets. Fuel Process. Technol. 2012, 103, 91-96.

17. Montero, I.; Miranda, M.T.; Arranz, J.I.; Rojas, C.V. Thin layer drying kinetics of by-products from olive oil processing. Int. J. Mollecular Sci. 2011, 12, 7885-7897.

18. Montero, I.; Blanco, J.; Miranda, M.T.; Rojas, S.; Celma, A.R. Design, construction and performance testing of a solar dryer for agroindustrial by-products. Energy Convers. Manag. 2010, 51, 1510-1521.

19. Augustus Leon, M.; Kumar, S.; Bjhattacharya, S.C. A comprehensive procedure for performance evaluation of solar food dryers. Renew. Sustain. Energy Rev. 2002, 6, 367-393.

20. El-Sebaii, A.A.; Aboul-Enein, S.; Ramadan, M.R.I.; El-Gohary, H.G. Experimental investigation of an indirect type natural convection solar dryer. Energy Convers. Manag. 2002, 43, 2251-2266.

21. Liu, Z.; Quek, A.; Balasubramanian, R. Preparation and characterization of fuel pellets from woody biomass, agro-residues and their corresponding hydrochars. Appl. Energy 2014, 113, 1315-1322.

22. De la Gómez Cruz, F.J.; Palomar, J.M.; Casanova, P.J.; Cruz, F. Experimental determination of effective moisture diffusivity during the drying of clean olive stone: Dependence of temperature, moisture content and sample thickness. Fuel Process. Technol. 2015, 137, 320-326.

23. Doymaz, I. Drying behaviour of green beans. J. Food Eng. 2005, 69, 161-165.

24. Babalis, S.J.; Belessiotis, V.G. Influence of the drying conditions on the drying constants and moisture diffusivity during the thin-layer drying of figs. J. Food Eng. 2004, 65, 449-458. 
25. Velic, D.; Planinic, M.; Tomas, S.; Bilic, M. Influence of airflow velocity on kinetics of convection apple drying. J. Food Eng. 2004, 64, 97-102.

26. Corvalan, R.; Horn, M.; Roman, R.; Saravia, L. Engineering Solar Drying; Science and Technology Program for Development of V Centenary (CYTED-D): Madrid, Spain, 1992.

27. Simate, I. Optimization of mixed-mode and indirect-mode natural convection solar dryers. Renew. Energy 2003, 28, 435-453.

28. Gögüs, F.; Maskan, M. Air drying characteristics of solid waste (pomace) of olive oil processing. J. Food Eng. 2006, 72, 378-382.

29. Madamba, P.S.; Driscoll, R.H.; Buckle, K.A. The thin-layer drying characteristics of garlic slices. J. Food Eng. 1996, 29, 75-97.

30. Bena, B.; Fuller, R.J. Natural convection solar dryer with biomass back-up heater. Solar Energy 2002, 72, 75-83.

31. El-Sebaii, A.A.; Aboul-Enein, S.; Ramadan, M.R.I.; El-Gohary, H.G. Empirical correlations for drying kinetics of some fruits and vegetables. Energy 2002, 27, 845-859.

32. Jain, D. Modeling the system performance of multi-tray crop drying using an inclined multi-pass solar air heater with in-built thermal storage. J. Food Eng. 2005, 71, 44-54.

33. Nijmenh, M.N.; Ragab, A.S.; Emeish, M.S.; Jubran, B.A. Design and testing of solar dryers for processing food wastes. Appl. Therm. Eng. 1998, 18, 1337-1346.

(C) 2015 by the authors; licensee MDPI, Basel, Switzerland. This article is an open access article distributed under the terms and conditions of the Creative Commons by Attribution (CC-BY) license (http://creativecommons.org/licenses/by/4.0/). 